\title{
Role of the capillary fringe on the dilatation of a low porosity limestone submitted to unidirectional freezing
}

\author{
Celine Thomachot-Schneider ${ }^{*}$ (D), Emilie Huby, Kevin Chalons, Xavier Drothière and Patricia Vazquez
}

\begin{abstract}
As a rule, usually only one face of the building stones of a monument is exposed to climatic variations. Penetration of temperature and humidity stress is unidirectional from the external surface while capillary absorption comes from the bottom part of the accumulation zones such as soil or cornice band. This configuration has to be taken into account in the setting of frost weathering tests in the laboratory. Formation of ice is accompanied by changed volumes and by movements of liquid water due to cryosuction. These phenomena lead to the dilatation of the porous network as assessed by strain gage monitoring. In this study, an experimental setting was developed to simulate the condition of a building stone submitted to frost and water supply by capillary absorption. Strain gages and thermocouples were attached to a limestone sample in order to assess thermal penetration and dilatation changes. Two types of saturation conditions were applied to the sample: water supply only by capillarity and water supply by capillarity after immersion during $48 \mathrm{~h}$. Freeze-thaw cycles of $24-\mathrm{h}$ freezing at $-15^{\circ} \mathrm{C}$ and $24-\mathrm{h}$ thawing at $+10{ }^{\circ} \mathrm{C}$ were performed. Results showed that deformation perpendicular to the freezing direction was negligible except for the fringe zone where it could reach $6 \times 10^{-4}$. In contrast, on both sides of the wet fringe, a deformation parallel to the freezing direction occurred, corresponding to an expansion upon freezing and a contraction upon thawing, with an intensity correlated in both cases to saturation. This original test also showed the importance of the capillary fringe in the frost action on building stones that is not taken into account in classical frost weathering tests. And it is to be noted that the strain gages allowed to measure immediate damage before it reached the inside of the stone and before it could be visually perceived.
\end{abstract}

Keywords: Frost weathering, Capillary fringe, Unidirectional freezing, Strain gages, Limestone

\section{Introduction}

Frost action is one of the major weathering factors of building stones. Freezing of the water inside the porous network causes dilatation as a result of a change in its volume (9\%) as well as of the movements of liquid water following cryosuction. Freezing in a porous network is not uniform (Thomas 1938). Water can remain liquid at temperatures below zero, a process called "supercooling" (Chahal and Miller 1965; Prick 1995). In this case, the freezing temperature depends on the pore size; the smaller the pore, the lower the freezing temperature (Everett 1961). The saturation state of the porous

\footnotetext{
* Correspondence: celine.schneider@univ-reims.fr

GEGENAA EA 3795, University of Reims Champagne-Ardenne (URCA), Reims, France
}

network is thus a critical parameter in the stress caused by the movement of water while freezing. In the event of a solute in the water, the solution can be cooled below the freezing point of the corresponding pure liquid, this being due to the presence of salts and called the "freezing point depression" (Conde et al. 2018). The freezing temperature of the water decreases depending on the salt content up to a minimum value corresponding to the eutectic point.

In a porous network saturated by capillary absorption, it is only its free porosity that is taken up by water while its trapped porosity (mainly macropores) remains occupied by air (Hirschwald 1912). In this case, the changed volume of the ice is accommodated by the trapped porosity and the ice crystallizes 
without generating any pressure (Powers 1948; Everett 1961; Litvan 1978). Friction resistance to the water movements following cryosuction is the main cause leading to an expansion or contraction of the porous network and thus to cracking (theory of hydraulic pressures of Powers 1948 and Litvan 1978). A high freezing rate, a large amount of available water and a long distance to reach a trapped pore will intensify the generated pressure. These water movements are irreversible and the water attracted by cryosuction remains in the macropores even during thawing. In the event of a water supply, the repeated cycles of freeze-thaw will lead to the increase of the amount of water in the porous network (Mc Greevy and Whalley 1985; Thomachot and Jeannette 2002). As a result, capillary saturation will progressively change into total saturation.

n a porous network totally saturated under vacuum, ice first grows within macropores but then because all the porous network is occupied by water, it has no longer any space to go on growing. It exerts a pressure on unfrozen water (Powers 1948) and when macropores are totally frozen, extrusion of ice toward the finer pores occurs and leads to so-called capillary pressures (Everett 1961). These pressures are proportional to the difference between the macropore radius and the bottleneck of the capillary.

In a monument, frost has the particularity of entering the stone only through the exposed facade. The surrounding blocks and the milder indoor conditions protect the other faces. To assess the effect of freeze-thaw on stones, standard tests are commonly used or adapted in terms of temperature or freezing time. All these tests, even the customized ones, consist in freezing the samples after prior immersion in water and thawing them in room temperature water (EN. 12371 2010; Tan et al. 2011; Ruedrich et al. 2011). All the stone faces are exposed to damage, yet these tests do not reproduce freeze-thaw conditions in situ.

These standardized tests estimate the decay produced by the ice as causing loss of material (visible or by weight measurements) and decrease in tensile strength. In both cases, if the test itself is not destructive enough to produce material detachment, these evaluation methods are irrelevant. In addition, these tests cannot be performed outside laboratories and in real monuments with immovable materials.

So in this study, we tested an alternative solution to these constraints thanks to a non-destructive setting that allowed freezing to be produced only on one face of the stone and to the use of strain gages attached along the stone as a way of assessing microscopical structural damage. This setting was tested on a common Lutetian limestone building in the surroundings of Reims (France).

\section{Methods/Experimental Materials}

In order to develop an experimental setting able to simulate the natural conditions of a building stone placed in elevation, a building stone sample was necessary. The Middle Lutetian limestone called Courville limestone was chosen for this study. It is a common building stone in Reims (France) and its surroundings (Fronteau et al. 2010). Actually, the famous Reims Cathedral or the St-Remi Basilica was originally built with Lutetian limestones (Turmel et al. 2014, Fig. 1a, b). One of the main weathering patterns observed on this building stone is the scaling of millimetric layers of stones placed in the capillary zone or in elevation, especially when placed as cornice band, column, or statues (ICOMOS, Fig. 1c). The angular parts of the blocks mainly suffer from scaling attributed to the alternation of wetting-drying cycles combined with the action of temperature variations. Nowadays, there are no more quarries. The last one located $20 \mathrm{~km}$ west of Reims was closed in 2005. The Courville limestone is a cream-colored packstone/wackestone presenting a heterogeneous micritic matrix, which was recrystallized into microsparite with mainly shells, miliolids, and Orbitolites complanatus formaminifera (Fig. 1d, e). In this study, the used Courville limestone belongs to the "Roche" bed, which is the less porous bed of the formation (Fronteau et al. 2002). This special type of Courville limestone was mainly used for the lower section of buildings. The porosity value of the studied block determined by mercury porosimetry is $11.2 \%$ with a mean pore radius of $0.05 \mu \mathrm{m}$ corresponding to a microporous network with a unimodal distribution (Fig. 2a). Capillary kinetics is quite low with values of $790 \mathrm{~g} \mathrm{~m}^{-2} \mathrm{~h}^{-1 / 2}$ for the coefficient relative to the

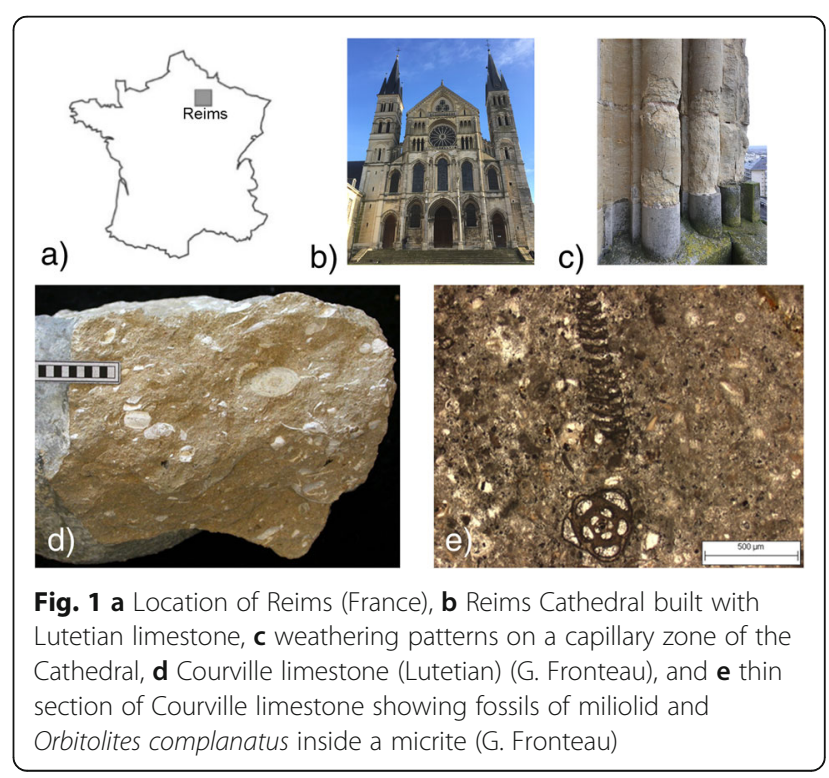




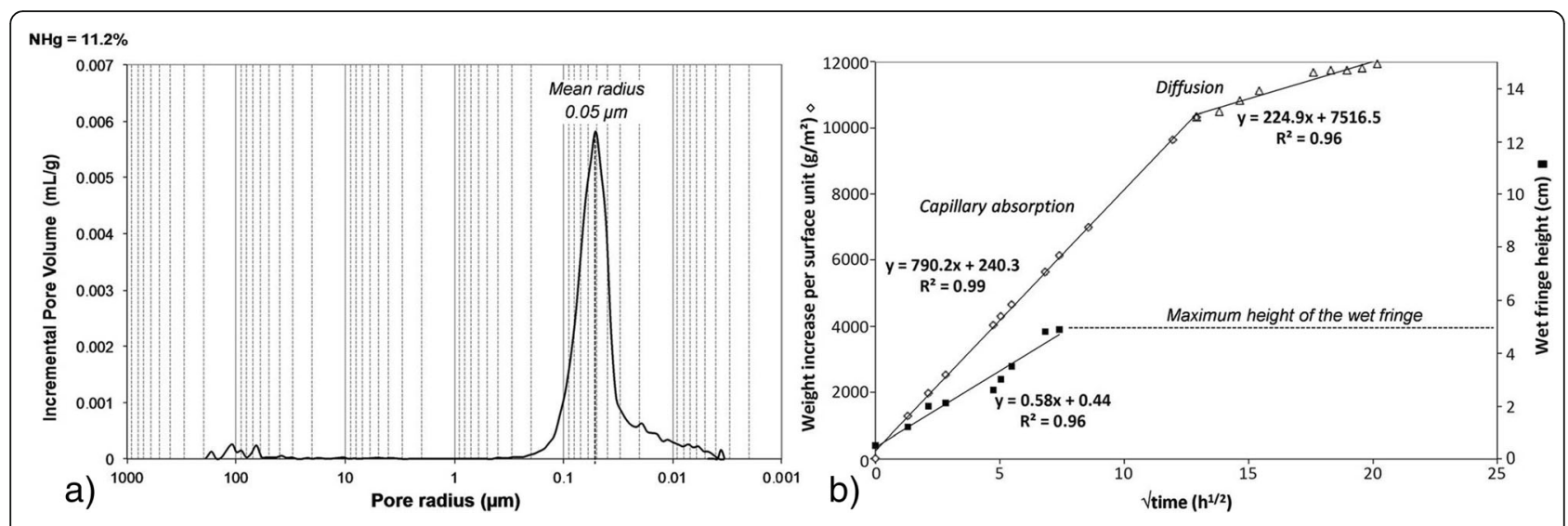

Fig. 2 a Pore distribution obtained by mercury injection porosimetry and $\mathbf{b}$ capillary kinetics of the Courville limestone "Banc Roche"

weight increase (first curve with diamond points in Fig. 2) and of $0.58 \mathrm{~m} \mathrm{~h}^{1 / 2}$ for the coefficient relative to the migration of the weight fringe (Fig. 2b). Due to a weak capillary transfer explaining its use for the low sections of buildings or pavements, the wet fringe of a $15-\mathrm{cm}$ high sample stopped at around a $6 \mathrm{~cm}$ height (Fig. 2b). Even if the visible wet fringe stops at a 6 -cm height after $50 \mathrm{~h}$, capillary

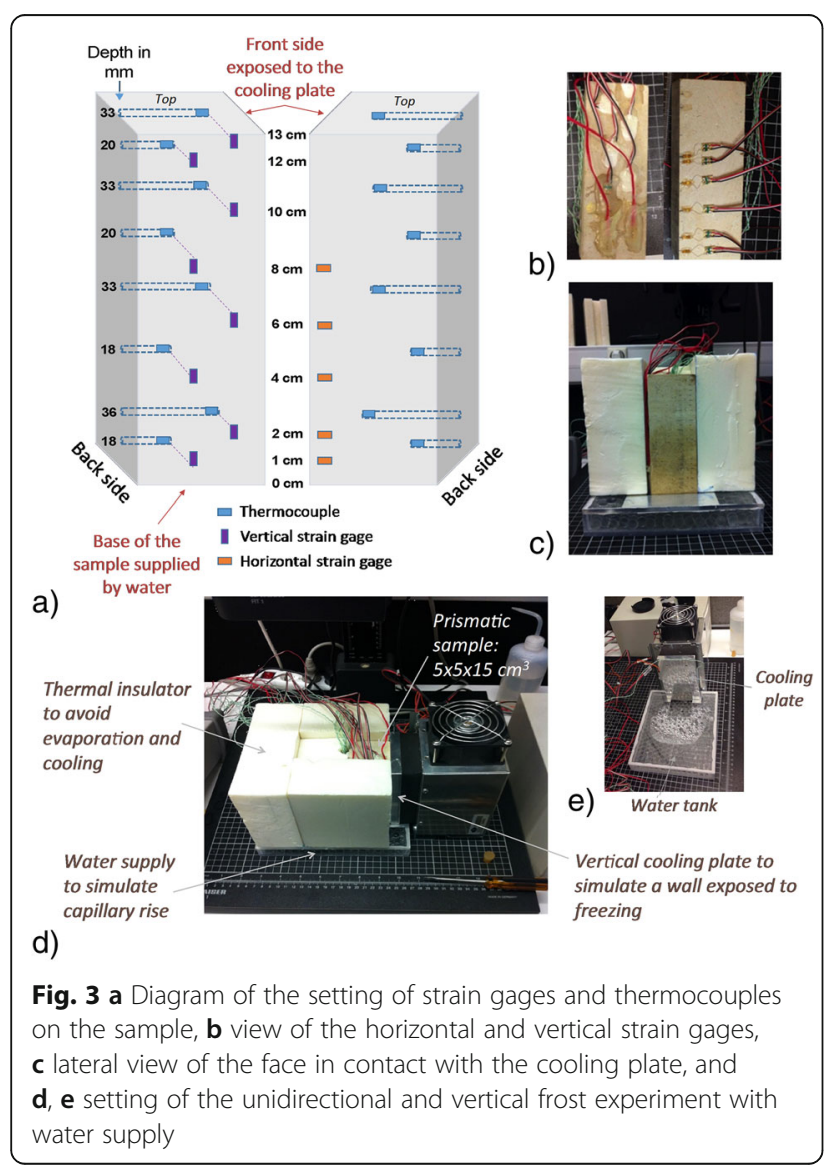

absorption continues as shown by the first curve of the weight increase per surface unit. The break of slope, corresponding to the end of the capillary absorption strictly speaking, occurs after $170 \mathrm{~h}$. The saturation of the porous network goes on by diffusion (curve with a weak slope).

\section{Experimental setting}

The aim of the setting was, as on the wall of the lower section of a building, to reproduce unidirectional freezing on the vertical face of a sample while keeping its other faces isolated, and with a capillary rise of water from the ground, supplied in it base.

To produce freezing, a cooling plate Tetech $\mathrm{J061}$ $(8 \times 13 \mathrm{~cm})$ of temperatures ranging from 80 to $-30{ }^{\circ} \mathrm{C}$ and a variation of $0.01{ }^{\circ} \mathrm{C}$ during the test was placed vertically in contact with one vertical face of the prismatic sample of $5 \times 5 \times 15 \mathrm{~cm}$. The rest of the faces

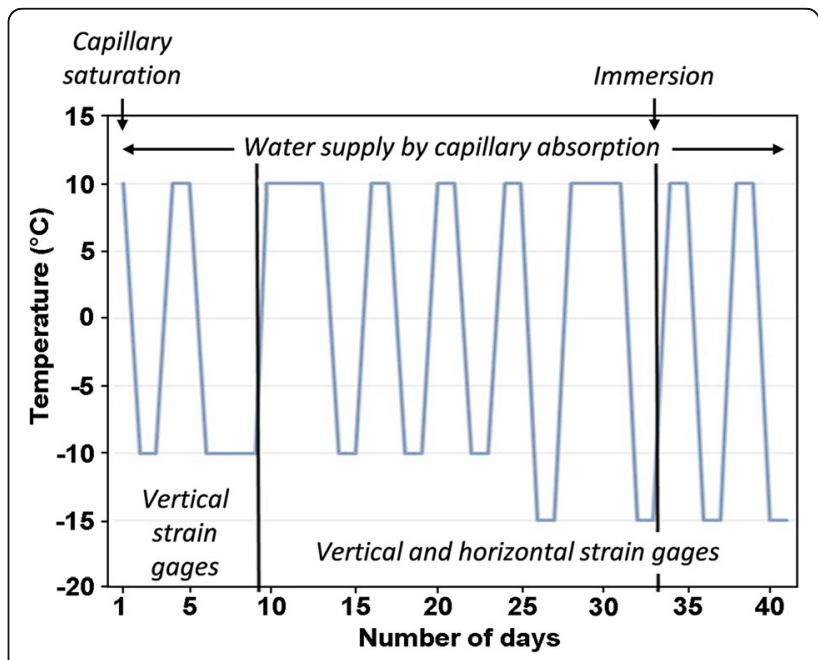

Fig. 4 Main conditions of the experiment 
was sealed with a thermal insulator to avoid evaporation and cooling (Fig. 3c, d).

To assess frost action, strain gages from Kyowa, KFWSS-2N-120-C1-11L3M2R, with a length of $2 \mathrm{~mm}$, a gage factor of 2.12 , and a resistance of $120.0 \pm 0.8 \Omega$, were set up at different heights of the sample with different orientations from the direction of freezing penetration. Strain gages measuring the vertical deformation were placed offset at 1 and $3 \mathrm{~cm}$ away from the face in contact with the cooling plate, at $1,2,4,6,8,10,12$, and $13 \mathrm{~cm}$ away from the bottom of the sample. Testing was first performed in this setting, and subsequently horizontal strain gages, placed perpendicularly to the cooling plate, were added at heights of $2,4,6$, and $8 \mathrm{~cm}$ on the opposite face, and $0.5 \mathrm{~cm}$ away from the surface in contact with the cooling plate (Fig. $3 \mathrm{a}-\mathrm{c}$ ).

To control the freezing penetration inside the sample, holes of $2 \mathrm{~mm}$ diameter were drilled at the same heights
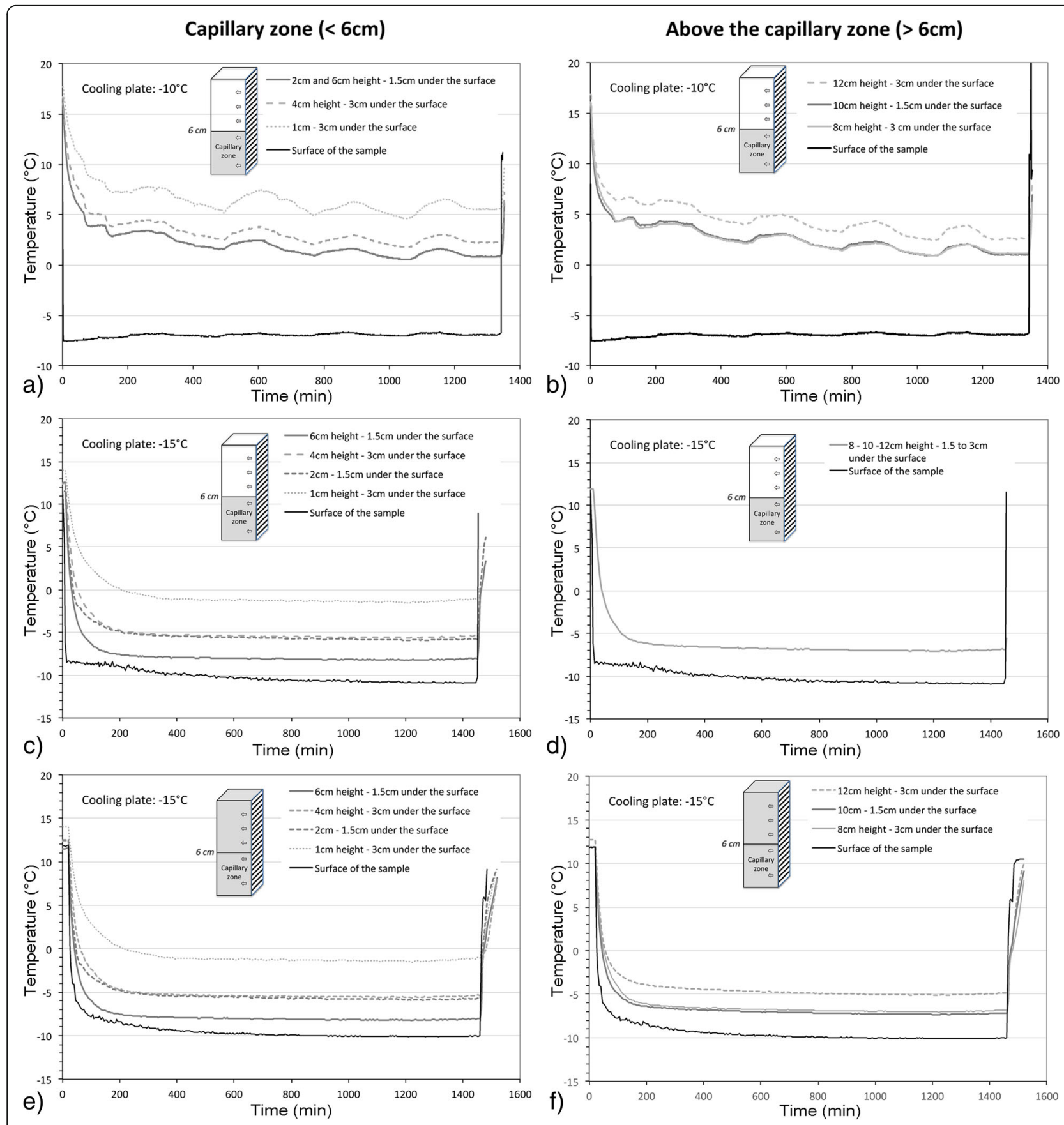

Fig. $\mathbf{5}$ Temperature kinetics inside the sample $\mathbf{a}, \mathbf{c}, \mathbf{e}$ in the capillary zone and $\mathbf{b}, \mathbf{d}, \mathbf{f}$ above the capillary zone 
as the strain gages but from the face opposite the one submitted to the cooling plate. Type $\mathrm{K}$ thermocouples with an accuracy of $0.1{ }^{\circ} \mathrm{C}$ were placed within them at depths corresponding to the location of the strain gage for control of the penetration of freezing within the stone. Even though this was a partially destructive method, it was necessary to confirm whether freezing was produced within the stone and at which moment, in order to establish the best experimental protocol. The data from the strain gages and thermocouples were recorded with an Agilent Data Logger 3. The data were obtained every 5 min by the interface Benchlink.

Before experimenting, the thermal dilatation of the stone was recorded on the dry sample. The thermal expansion coefficient alpha expresses the expansion of a material as a function of temperature. The linear coefficient of thermal expansion for the investigated samples was calculated from the experimentally determined temperature and dilatation data (alpha $=$ Delta $L / L^{*}$ Delta $T: T$ is temperature and $L$ is length). Temperature was set at $+40{ }^{\circ} \mathrm{C}$ and then down to $-15{ }^{\circ} \mathrm{C}$ to determine the average coefficient.

As regards freezing testing, two kinds of water saturation were tested: (i) partial saturation obtained by continuous capillary water supply, and (ii) partial saturation obtained by a previous 48 -h total immersion. Freeze-thaw cycles were divided into $24 \mathrm{~h}$ freezing periods at $-10{ }^{\circ} \mathrm{C}$ for the first five cycles then at $-15{ }^{\circ} \mathrm{C}$ for the next five cycles and $24 \mathrm{~h}$ thawing periods at $+10{ }^{\circ} \mathrm{C}$ (Fig. 4). The whole experiment was repeated two times. During the whole time of the two tests, water was supplied to the sample by capillary absorption from a bottom water tank.

\section{Results and discussion}

For the first five cycles, the temperature of the cooling plate was set at $-10{ }^{\circ} \mathrm{C}$. The temperature recorded at the surface of the sample was around $-6.7{ }^{\circ} \mathrm{C}$ (Fig. 5a, b). This temperature was enough to freeze only the surface of the sample and the first centimeter in depth, but freezing did not reach the inner part of the sample. Thermocouples placed at 1.5 to $3 \mathrm{~cm}$ in depth did not record temperatures lower than around $1{ }^{\circ} \mathrm{C}$. Regarding the distribution of temperature extrapolated from the thermocouple data (Fig. 6a), the maximum for freezing was reached in the central part of the sample surface corresponding to a 4 to $8 \mathrm{~cm}$ height. This temperature distribution was similar in the other types of settings. This was due to a side effect of the cooling plate, the efficiency of which was maximum in the center. The time necessary to reach a stable temperature in the sample was between 2 and $3 \mathrm{~h}$ according to the thermal conductivity of the sample (Fig. 6).

For the next five cycles, the temperature was set at $15{ }^{\circ} \mathrm{C}$. This allowed to reach a temperature of $-10{ }^{\circ} \mathrm{C}$ at the surface of the sample and of $0{ }^{\circ} \mathrm{C}$ at around $3.5 \mathrm{~cm}$ in depth whatever the saturation of the sample (Figs. $5 \mathrm{a}, \mathrm{d}-\mathrm{f}$

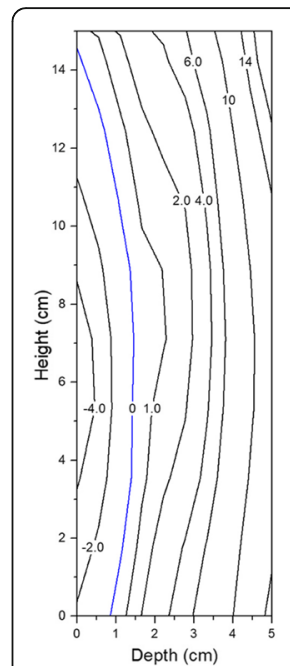

a) Imbibition $-10^{\circ} \mathrm{C}$

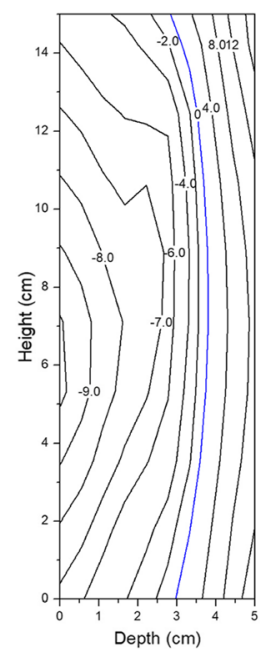

b) Imbibition $-15^{\circ} \mathrm{C}$

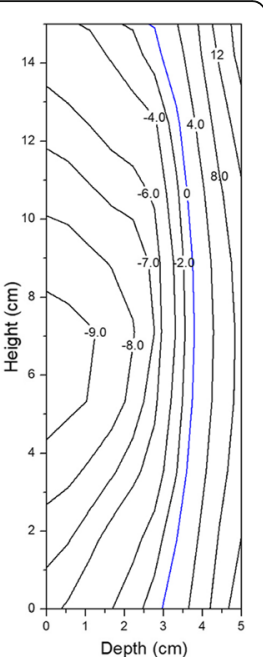

C) Immersion $-15^{\circ} \mathrm{C}$
Fig. 6 Temperature mapping inside the sample after a capillary absorption and freezing at $-10^{\circ} \mathrm{C}, \mathbf{b}$ capillary absorption and freezing at $-15^{\circ} \mathrm{C}$, and $\mathbf{c}$ after immersion and freezing at $-15^{\circ} \mathrm{C}$

and $6 \mathrm{~b}, \mathrm{c})$. This difference in surface temperature of $3{ }^{\circ} \mathrm{C}$ between the two settings $\left(-10\right.$ and $\left.-15^{\circ} \mathrm{C}\right)$ led to a $2 \mathrm{~cm}$ change in frost penetration even if the kinetics of penetration was similar. The time necessary to reach a stable temperature inside the sample was also between 2 and $3 \mathrm{~h}$. The gradient of temperature inside the sample was similar for both types of saturation (capillary and immersion). Due to its low porosity (11.2\%) and low capillary saturation, the saturation of the Courville limestone by simple immersion was not enough to disturb significantly the heat conduction in the sample. In a porous network, a $0{ }^{\circ} \mathrm{C}$ temperature does not mean systematically that water is frozen. Water can remain in a liquid state at a temperature below $0{ }^{\circ} \mathrm{C}$, this being called supercooling (Chahal and Miller 1965). Supercooling, and thus the freezing temperature of water inside a porous network, depends on the size of the pores: the smaller the pores, the lower the freezing temperature (Everett 1961; Blachère 1975). For example, Tourenq (1970) determined a freezing temperature around -2 to $-4{ }^{\circ} \mathrm{C}$ for stones with main porosity larger than $0.03 \mu \mathrm{m}$ while Fagerlund (1971) determined freezing temperature around 0 to $-3{ }^{\circ} \mathrm{C}$ for stones with main porosity ranging from 0.02 to $0.5 \mu \mathrm{m}$. The mean radius of the studied limestone is around $0.05 \mu \mathrm{m}$ which means that freezing should occur at temperatures around $-2{ }^{\circ} \mathrm{C}$. According to the gradient of temperature (Fig. 6), with a cooling plate set at $-10^{\circ} \mathrm{C}$, the freezing front, corresponding to the zone cooled at temperatures below $-2{ }^{\circ} \mathrm{C}$, remained superficial (less than $0.5 \mathrm{~cm}$ in depth) (Fig. 6a). For the two other settings at $-15{ }^{\circ} \mathrm{C}$ with capillary absorption only and after immersion, the zone cooled under $-2{ }^{\circ} \mathrm{C}$ was deeper and corresponded to the first $3 \mathrm{~cm}$. 
The thermal dilatation of the stone was recorded on the dry sample at temperature ranging from room temperature to $+40{ }^{\circ} \mathrm{C}$ and then from room temperature to $-15{ }^{\circ} \mathrm{C}$. It showed values respectively of $+1.2 \mathrm{~mm} / \mathrm{m}$ and $-3.0 \mathrm{~mm} / \mathrm{m}$, which corresponded to thermal coefficients ranging from 1.0 to $2.0 \times 10^{-6} / \mathrm{K}$. These values were of the same order of magnitude as those measured by other authors on limestone, sandstone, porphyry, tuff, or granite (Thomachot and Jeannette 2002; Ruedrich et al. 2011).

During the first part of the freezing test, the sample was partially saturated by capillary absorption. The weak capillary properties of this Lutetian bedding ("Banc
Roche") due to its low porosity mainly made of microporosity, explained why the wet fringe on the $15 \mathrm{~cm}$ long prismatic sample did not reach a height of $6 \mathrm{~cm}$ or more. Differential dilatation behavior between the capillary zone and the upper dry zone was expected.

In the second part of testing when the sample was saturated by immersion during for $48 \mathrm{~h}$, a more homogeneous deformation along the sample was expected even if the sample was still supplied by capillary absorption from the bottom.

Dilatation recorded by the vertical strain gages during the freeze-thaw cycles with the cooling plate set at $-10{ }^{\circ} \mathrm{C}$ was negligible. The sensors, placed along the sample, were
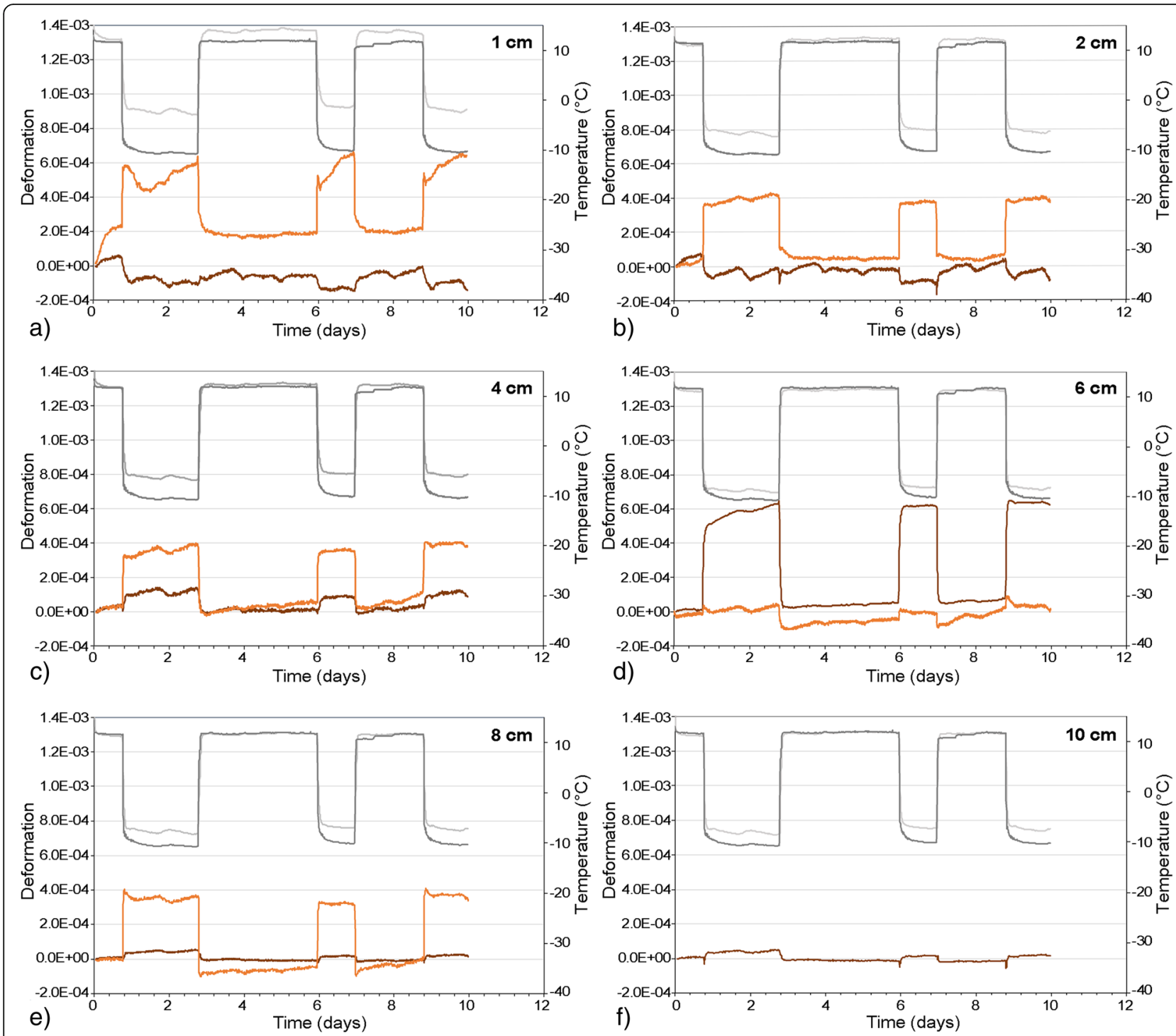

-Vertical deformation _- Horizontal deformation —Temperature in depth —Surface temperature

Fig. 7 Main horizontal and vertical dilatation behavior according to freeze-thaw cycles and corresponding temperature of the surface and in depth at the level of the strain gage at $\mathbf{a} 1 \mathrm{~cm}, \mathbf{b} 2 \mathrm{~cm}, \mathbf{c} 4 \mathrm{~cm}, \mathbf{d} 6 \mathrm{~cm}, \mathbf{e ~} 8 \mathrm{~cm}$, and $\mathbf{f} 10 \mathrm{~cm}$ 
too far away from the ice front located in the first millimeters of the surface. A significant expansion of $1.2 \times 10^{-4}$ was recorded only by the strain gage at $6 \mathrm{~cm}$ height during freezing.

Results of freeze-thaw cycles with the cooling plate set at $-15{ }^{\circ} \mathrm{C}$ showed that whatever the saturation of the sample, the dilatation behavior was not homogeneous along the sample and that it could be divided into three parts corresponding to the capillary zonation: the capillary zone $(0-6 \mathrm{~cm}$, Fig. $7 \mathrm{a}-\mathrm{c})$, the fringe limit $(6 \mathrm{~cm}$, Fig. $7 \mathrm{~d})$, and the upper zone not soaked by capillary absorption during the test $(>6 \mathrm{~cm}$, Fig. $7 \mathrm{e}, \mathrm{f})$.

In the capillary zone and the upper zone, the dilatometric behavior recorded was similar. The deformation perpendicular to the freezing direction (vertical strain gages) was negligible while the deformation parallel to the freezing direction corresponded to an expansion during freezing and a contraction during thawing. Values of expansion were close to $4 \times 10^{-4}$ whatever the position of the strain gage. In the zone of the capillary fringe, the behavior was opposite: the deformation parallel to the freezing direction (horizontal strain gages) was negligible while the vertical deformation reached $6 \times 10^{-4}$ expansion during freezing (Fig. 7b). During freezing, no contraction was recorded before expansion suggesting that no supercooling occurred.

The different dilatation behavior depending on the orientation of the freezing front showed that the deformation was mainly unidirectional (Fig. 8). Indeed, the deformation did not occur in all directions but was conditioned by the combination of the water flux around the water fringe and the freezing front. When a stone is submitted to a previous imbibition, the water is homogeneously distributed through the porous network, and when the temperature decreases sufficiently for water to freeze, the deformation of the stone will follow the penetration of the freezing front. A deformation perpendicular to the freezing front along the sample was thus expected: indeed, this corresponds to the expansion of ice when crystallizing and growing deeper in the porous network as associated to cryosuction of remained liquid water toward the ice front (Matsuoka 1990; Weiss 1992; Prick 1996; Thomachot et al. 2005). The presence of water supply during the experiment introduced another water flow perpendicular to the freezing front whose effect was increased by the $6 \mathrm{~cm}$ height threshold of the capillary fringe. In a capillary absorption, the repartition of water inside the stone is not homogeneous: the saturation is higher at the bottom of the sample supplied by water and at the level of the capillary fringe (Tournier 2001). Initially, the capillary fringe zone was more saturated than the other parts of the sample. Furthermore, the water supply during the freezing test

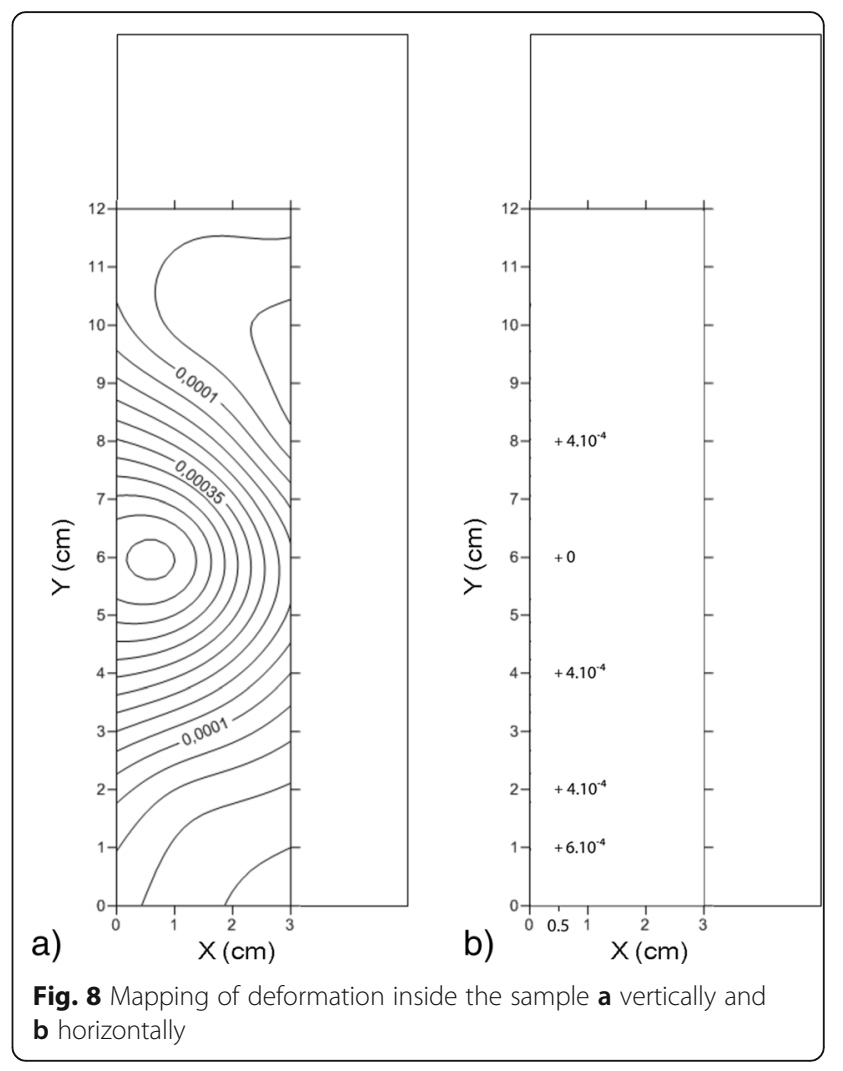

enables cryosuction and leads to an increase of stone saturation (Mc Greevy and Whalley 1985). This water concentration interface inside the stone was enough to cause vertical expansion even if the freezing was superficial (cooling plate temperature at $-10{ }^{\circ} \mathrm{C}$ ). With a stronger freezing $\left(-15{ }^{\circ} \mathrm{C}\right)$, the vertical expansion, perpendicular to the frost penetration, was maximum at the wet fringe zone due to the maximum water content and the water flux associated to capillary rise and cryosuction. A higher amount of ice crystallizing extruded toward less saturated zones led to a strain increase stronger than in less saturated parts. This phenomenon was accentuated by the fact that the cooling plate was more efficient in the central part that corresponds to the wet fringe. The penetration of the freezing front was faster and stronger in the part corresponding to the capillary fringe zone. Thus extrusion of ice during the freezing penetration caused dilatation on both sides of the wet fringe (upward and downward), causing vertical deformation.

When combining values of the different strain gages, it appears that deformation at the capillary fringe $(6 \mathrm{~cm})$ was opposite to the 2 and $10 \mathrm{~cm}$ one below and above the capillary fringe $(4$ and $8 \mathrm{~cm}$ ), deformation was transitional with both directions of deformation (Fig. 8).

The lack of difference between dilatation after capillary absorption or immersion showed that the liquid within 
the pore space had no influence in the dilatation behavior of this limestone.

The opposite strains developed around the capillary fringe (Fig. 9) led to quite a lot of strains in this zone. A stone submitted to ice pressure would be subjected to an increase of porosity by cracking or widening of the pores. This implies that with a number of freeze-thaw cycles, the porosity of the fringe zone will increase as well as its saturation. If because of a modification of the porous network the maximum height of the wet fringe changes positions, the sensitive zone will increase with time. The zone submitted to a differential expansion will extend and consequently a larger part of the stone will be more prone not only to frost weathering but also to salt crystallization and drying impact inside the stone, and thus increase scaling as observed in monuments (Fig. 1c).

The stone tested is a homogeneous limestone in which the anisotropy of the capillary rise is weak to null. However, in the case of an anisotropic stone such as one of several limestones and sandstones, the damage produced by capillary frost weathering will be more evident. In elevations, stones are placed in a horizontal bedding while they are placed vertically when used for columns or rails. Capillary kinetics are usually higher when parallel to the bedding. The water movements associated to the

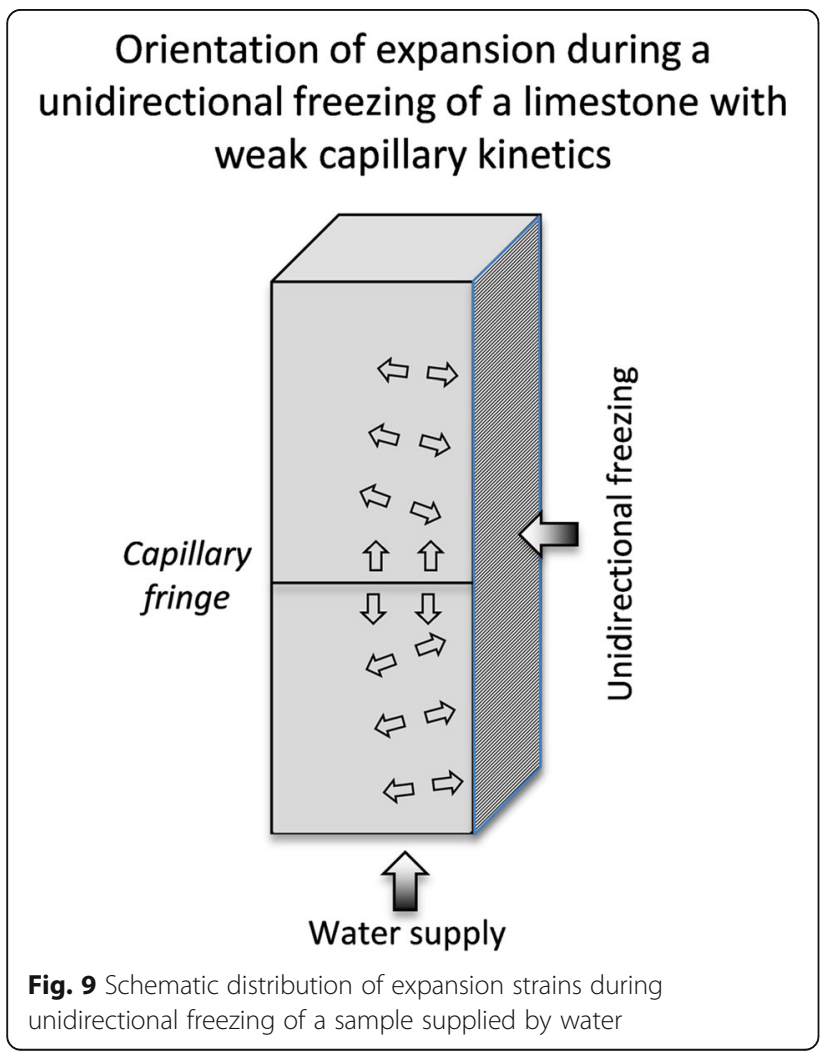

freezing front will be easier and will cause less strain in the horizontal direction in blocks in elevations and in the vertical direction in columns or rails. The repartition and intensity of strain around the capillary fringe as shown in this study will change accordingly. Further experiments simulating rain with a water supply on the external surface would complete the display of strain caused by climatic changes in buildings.

\section{Conclusions}

Strain gages are a very accurate non-destructive technique that could be applied in real stone monuments. They measure the mechanical stress produced on their surface not only by ice but also by temperature changes or liquid water movements. The gages provide reliable measurement of the immediate damage before it reaches the inside of the stone and before its visual and irreversible degradation.

This original test shows the importance of the zone around the capillary fringe in the frost action on building stones. Around this zone, the directions of dilatation in the stone are opposite to the rest of the sample. This could lead to the growth of high mechanical stress on the fringe zone, making it more sensitive to frost action.

\section{Abbreviation}

GEGENAA: Groupe d'étude des géomatériaux naturels, anthropiques et archéologiques

\section{Acknowledgements}

CTS and PV gratefully acknowledge PEPS grant to attend the JpGU symposium 2017 held at Tokyo, Japan. KC gratefully acknowledges American Geoscience Union travel grant to attend the J.JGU symposium 2017 held in Tokyo, Japan. Our thanks to A Thomachot for her editing assistance.

\section{Funding}

This work was supported by GEGENAA EA 3795, URCA, and Grand Reims through the Remitherm project.

\section{Availability of data and materials}

Please contact author for data requests.

\section{Authors' contributions}

CTS proposed the topic, conceived and designed the study. KC, EH, and XD carried out the experimental study. CTS, KC, and EH analyzed the data and helped in their interpretation. PV collaborated with the corresponding author in the construction of the manuscript. All authors read and approved the final manuscript.

\section{Authors' information}

CTS and PV are assistant professors at Reims University in a laboratory (GEGENAA EA-3795) involved in understanding and providing solutions to the weathering mechanisms of building materials. EH and KC are respectively $\mathrm{PhD}$ and Bachelor students who work on the thermal behavior of building stones. This study is the result of their work.

\section{Competing interests}

The authors declare that they have no competing interests.

\section{Publisher's Note}

Springer Nature remains neutral with regard to jurisdictional claims in published maps and institutional affiliations. 
Received: 8 February 2018 Accepted: 30 August 2018

Published online: 07 November 2018

\section{References}

Blachère JR (1975) Le gel de l'eau dans les matériaux poreux. Vlème Congrès international F.F.E.N, Le Havre, pp 296-303

Chahal RS, Miller RD (1965) Supercooling of water in glass capillaries. Br J Appl Phys 16:231-239

Conde MM, Rovere M, Gallo P (2018) Molecular dynamics simulations of freezingpoint depression of TIP4P/2005 water in solution with $\mathrm{NaCl}$. J Mol Liq 261(2018):513-519

EN.12371 (2010) Natural stone test methods-determination of frost resistance. In: European standard

Everett DH (1961) The thermodynamics of frost damage to porous solids. Trans Faraday Soc 57:1541-1551

Fagerlund G (1971) Degré critique de saturation: un outil pour l'estimation de la résistance au gel des matériaux de construction. Matériaux et Constructions RILEM 4(23):271-283

Fronteau G, Moreau C, Thomachot-Schneider C, Barbin V (2010) Variability of some Lutetian building stones from the Paris Basin, from characterization to conservation. Eng Geol 115:158-166

Fronteau G, Pascal A, Barbin V (2002) Characterization of Courville stone (Lutetian, Marne, France). Relations between diagenesis and petrophysical properties, Géologie de la France 4:51-59

Hirschwald J (1912) Handbuch der bautechnischen Gesteinsprüfung, Berlin Borntraeger. Illustrated glossary on stone deterioration patterns, ICOMOSISCS. isbn:978-2-918086-00-0

Litvan G.G. (1978) Freeze-thaw durability of porous building materials, in durability of building materials and components, special technical publication STP 691. American Society for Testing and Materials 9:455-463

Matsuoka N (1990) Mechanisms of rock breakdown by frost action, an experimental approach. Cold Reg Sci Technol 17:253-270

Mc Greevy JP, Whalley WB (1985) Rock moisture content and frost weathering under natural and experimental conditions, a comparative discussion. Arct Alp Res 17(3):337-346

Powers TC (1948) The air requirement of frost-resistant concrete. Proc Highway Rese Board 29:184-211

Prick A (1995) Dilatometrical behaviour of porous calcareous rock samples subjected to freeze-thaw cycles. Catena 25:7-20

A. Prick (1996) La désagrégation mécanique des roches par le gel et l'haloclastie, Thèse de Sciences géographiques de l'Université de Liège

Ruedrich J, Kirchner D, Siegesmund S (2011) Physical weathering of building stones induced by freeze-thaw action: a laboratory long-term study. Environ Earth Sciences 63(7):1573-1586

Tan X, Chen W, Yang J, Cao J (2011) Laboratory investigations on the mechanical properties degradation of granite under freeze-thaw cycles. Cold Reg Sci Technol 68:130-138

Thomachot C, Jeannette D (2002) Evolution of the petrophysical properties of two types of alsatian sandstone subjected to simulated freeze thaw conditions. Geol Soc Spec Publ 205:19-32

Thomachot C, Matsuoka N, Kuchitsu N, Morii M (2005) Frost damage of bricks composing a railway tunnel monument in Central Japan: field monitoring and laboratory simulation. Nat Hazards Earth Syst Sci 5(4):465-476

W.N. Thomas (1938) Experiments on the freezing of certain buildings materials, Building Research, Technical Paper 17

C. Toureng (1970) La gélivité des roches, application aux granulats, Rapport de Recherche N6 LCPC

Tournier B (2001) Transferts par capillarité et évaporation dans des roches : rôles des structures poreuses, Thèse de doctorat de l'Université Louis Pasteur de Strasbourg, p 204

Turmel A, Fronteau G, Thomachot-Schneider C, Moreau C, Chalumeau L, Barbin V (2014) Stone uses in Reims cathedral: provenance, physical properties and restoration phases. Geol Soc Lond Spec Publ 391(1):17-30

Weiss G (1992) Die Eis und Salzkristallisation im Porenaum von Sandsteinen und ihre Auswirkungen auf das Gefüge unter besonderer Berücksichtigung gesteinsspezifischer Parameter. Münchner Geowissenschaftiche Abhandlungen B 9:118

\section{Submit your manuscript to a SpringerOpen ${ }^{\circ}$ journal and benefit from:}

- Convenient online submission

- Rigorous peer review

- Open access: articles freely available online

- High visibility within the field

- Retaining the copyright to your article

Submit your next manuscript at $\boldsymbol{\nabla}$ springeropen.com 